\title{
Leadership to Build Learning Communities
}

\author{
by Sally J. Zepeda
}

Learning communities cannot exist without leadership that facilitates teacher growth. Oxley $(1997,625)$ indicated that learning communities need "a unifying conceptual framework that binds them together into a coherent program of school-wide restructuring." Enduring learning communities are grounded in three foundations: (1) a culture based on human values; (2) a set of practices for generative conversation; and (3) a capacity to see and work with the flow of life as a system (Kofman and Senge 1993). Generative conversation in a learning community acts as the "glue" to "affirm its values and its membership, and infuse it with the energy, imagination, and commitment of the group" (Sterling 1998, 66).

Leadership solely by the principal, however, is not enough. A professional community is one "in which the teachers in a school and its administrators continuously seek and share learning, and act on their learning" (Hord 1997, 1). Principals should be "leaders of leaders rather than sole leaders"(Crow, Mathews, and McCleary 1996, 44) where "the entire school community - teachers, staff, principal, students, and parents-develops habits of continual learning-study, plan, act, reflect, and refine learning as a cycle" (Speck 1999, 5). Teachers learn from a variety of sources. Learning can be formal (e.g., graduate coursework), informal (e.g., watching a colleague teach a lesson), planned by others (e.g., traditional staff development and supervision), or self-directed by the teacher (e.g., individually guided action research). Regardless of the type of learning, it should be viewed as "an active practice that occurs over time ... fueled by rich, diverse, accessible sources of information" (Wald and Castleberry 2000, 9).

For adults, Brookfield $(1986,29)$ believed, "learning is further enhanced by regular feedback on progress, and positive feedback serves as a reinforcement for the pursuit of more learning." Brookfield (1995, 222) indicated that feedback needed to be followed by purposeful reflection on practice, and that reflection is a "uniquely adult form of learning." Supervision literature stresses the importance of dialogue to promote growth and development (Glickman, Gordon, and Ross-Gordon 1998), enhance sense making (Zepeda 2000), and foster the interchange of ideas between professionals (Waite 1995). Glickman et al. (1998, 6-7) proposed that supervision was the "glue of a successful school" and that this "ad-

Sally J. Zepeda is Associate Professor and Graduate Coordinator in the Department of Educational Administration and Policy at the University of Georgia. Her research focuses on instructional supervision. Dr. Zepeda is a member of the Illinois Golden A pple Chapter of Kappa Delta Pi. 
hesive pulls together organizational goals and teacher needs, and provides for improved learning."

\section{The Study}

This study examined the work of a principal of a Midwestern urban elementary school who used instructional supervision as a means of developing a learning community for adults. Implementing a variety of approaches adapted to the culture of the school, the principal crafted a process to meet the learning needs of 125 teachers and created an environment conducive to staff development. Also examined are other complementary practices in relation to the interconnected nature of supervision and staff development.

\section{Data Source and Context}

This study was conducted over a twoyear period at Plymouth Elementary School, one of 23 elementary schools located in an urban school district. The school has an enrollment of approximately 1,100 students (grades 1-5). In 1999, Plymouth Elementary School employed 125 teachers and staff members. Faculty members had an average of 14 years of teaching experience.

The year before the study, Plymouth Elementary School underwent a change in leadership. Ms. Pat Deci was named the new principal, replacing someone who had held that office for nine years. The new assistant principal, Mr. Al Jackson, replaced a person who had held that office for seven years. Deci and Jackson wanted to restructure the school into a learning community for its teachers. They were motivated by the negative results of a survey on the on-site professional growth opportunities provided by the school. Deci and Jackson were encouraged further by the reception they received when they walked into teachers' classrooms unannounced to do informal observations.

\section{Supervision and Professional DeVelo pment}

Before the movement to create a learning community, supervision at Plymouth Elementary School was pro forma with a single observation to evaluate teachers at year-end. Pre- and post-observation conferences were sporadic. Dialogue consisted primarily of discussing the state-mandated assigned rating for the year. The faculty regularly participated in staff development opportunities at the district level. However, the processes inherent in supervision, staff development, and teacher evaluation were not connected and were unrelated to meeting objectives in the site-level school improvement plan or the five-year strategic plan.

\section{Methods}

A case-study approach (Merriam 1998) was used to generate detailed descriptions of how the principal used supervision as a "glue" to promote the development of a learning community. Data were collected during a two-year period through multiple methods: on-site observations, interviews with teachers and administrators, and artifact collection and analysis.

The constant comparative method of analysis (Glaser 1978) was used to enable concurrent collection and analysis of data (Glaser and Strauss 1967). A coding and notation process was used to classify and further define and categorize concurrent themes in the data. Clarification of data was achieved through comparison of findings across data sets and follow-up discussions with a random sampling of participants (Guba 1981).

\section{Findings}

The supervision that promoted the development of a community of learners at Plymouth Elementary School centered on changing leadership paradigms that lead 
to inquiry, generative problem solving, dialogue, and reflection.

\section{The Context of Changing Leadership Paradigms}

Deci and Jackson challenged the structures supporting compliance-driven supervision because they wanted to eliminate the negative effects of evaluation (Acheson and Gall 1997) and the defensive stance teachers took when they entered their classrooms. Supervision needed to become a process that would have impact, with teachers actively involved to derive benefit and value from the processes. Supervision needed to be tied to other activities such as staff development. Supervisory practices also needed to be aligned with the organization and serve as a mechanism to meet the goals of the school improvement plan and its strategic five-year plan.

Deci and Jackson examined the role teachers could fulfill in their own growth. They came to grips with relinquishing their positions of authority by visioning what it would be like to have teachers visiting one another's classrooms. Given the expertise of their faculty members, Deci and Jackson knew that a more inclusive and collaborative form of supervision could move the school forward and serve as the backbone in creating a learning community. To begin the process, Deci and Jackson established a committee to explore professional development options. Within one year, Plymouth Elementary School:

- initiated a voluntary peer-coaching program;

- instituted a process whereby every teacher was observed by either a peer or an administrator at least four times a year;

- tied supervision to staff development;

- developed a school-wide committee to link professional development activities to the school improvement process and the goals in the strategic five-year plan; and

- established a site-based governing board to help make critical decisions affecting the school.

These activities helped Plymouth Elementary School become a learning community.As Sergiovanni $(1994,218)$ reported, "the ties of community become substitutes for formal systems of supervision, evaluation, and staff development." At the end of the first year, traditional structures of supervision at Plymouth Elementary had been replaced. Peer coaching was used by those teachers who opted to be involved in supervision mediated by their colleagues. This type of coaching was instituted as a means of extending supervision beyond what the principal or assistant principal did.

For teachers who did not want to participate in the peer-coaching program, Deci and Jackson conducted four cycles of clinical supervision (reference) before assigning an end-of-the-year summative evaluation rating. Each cycle included a pre-observation conference, an extended classroom observation (approximately 45 minutes), and a post-observation conference (Acheson and Gall 1997).

Principal Deci struggled with her involvement in these activities:

The work we do has to belong to the teachers; otherwise, they will think 
they're Deci's ideas and we better support them. Yet, I need to support their work. How can I support their work and not be involved in the process?

Throughout the year, both Deci and Jackson dealt with the challenges associated with the move toward a more inclusive community. Their ability to "let go," however, signaled to the faculty that the administrative team was willing to change. Supervision provided a baseline of experiences for teachers to inquire, talk, and reflect about their learning and what this learning meant to school improvement.

\section{INQUIRY}

Teachers were given the opportunity to inquire about their practices and the impact they had on students. One teacher said, "I feel that I am asking myself questions about why I do what I do."

Inquiring about practice was not always an easy task for the teachers at Plymouth Elementary School. They had to learn how to "tinker" with changing practices, and to learn how to trust and have confidence in one another. Another teacher reported, "I can think deeply about my practices. ... Others now are interested in what I have to say."

Generative learning is critical in the inquiry process. This type of learning "encourages learners to solve problems actively, by conducting meaningful inquiry, engaging in reflection, and building a repertoire of effective strategies for learning in diverse social contexts" (Jones, Valdez, Nowakowski, and Rasmussen 1994,3). Learners are encouraged to construct and produce knowledge in meaningful ways through the acknowledgment of prior experiences. Generative learning environments promote deep, engaged learning (Lambert 2003).

Staff development began to take on a different look. Teachers became involved in planning staff development opportunities, by forming a staff development committee with representation from every grade level. "Staff development became more than just counting sdu's [staff development units]," according to one teacher. "We identified things we wanted to learn in order to improve our practices." Ms. Deci indicated that there was a 32 percent increase in the number of requests to attend professional conferences, and that the staff development committee designed a survey to find out what classroom practices teachers wanted to tackle for the next year.

\section{Generative Problem Solving}

Conversations about teaching changed at Plymouth Elementary School. By following through with pre- and post-observation classroom conferences, Deci and Jackson broadened discussion from "what is my rating for the year" to "problem-posing and problem-solving" conferences. Through purposeful post-observation classroom conferences, where data from extended classroom observations served as starting points for ongoing discussions, teachers reported that they were in charge of their learning, and they could see and develop numerous ways of refining their practices. One teacher reported that she felt like a master craftsperson because she could see multiple ways of better addressing an aspect of her teaching.

Generative conversations became a reality through peer coaching. According to one teacher, "The [post-observation] talks with my coach helped me feel like I am part of the school .... Someone really cares what I do in my classroom." Another teacher said, "What I see other teachers doing in their classroom[s] makes me want to try new ideas. Our lunch periods now are filled with the "talk of teaching.'"

Weekly faculty meetings were restructured so that the first 20 minutes were re- 
served for "Talk about Teaching." This time gave teachers the opportunity to discuss important classroom/instructional issues, and provided a forum for teachers to talk with one another, pose problems, and generate new solutions. Deci had two ground rules: the talk had to be centered on an issue of practice; and solutions had to be generated. The teachers offered another ground rule: time for follow-up discussion had to be allowed at subsequent meetings.

Prior to the restructuring, faculty meetings ended within an hour. By the end of the first year, faculty meetings averaged an hour and a half with several teachers still in the library two hours later. When Deci tried to move the "Talk about Teaching" to the last 20 minutes of the faculty meetings, teachers were opposed to the idea. As one teacher said:

We need time to talk with adults. We need time to hear what others are doing. We need time to get down to solving the issues we face-together.

Teachers reported that now they were talking with one another about issues they faced in their classroom practices. One teacher said, "It's great getting so many perspectives. With so many points of view being shared, I can frame the issues better, and multiple solutions get put out there." A few teacher-generated action research projects allowed teachers to track changes in instructional practices to student learning gains.

Problem solving moved from the immediate issues of individuals to issues that the entire school faced. As Deci explained:
Teachers moved away from 'me and $I$ ' to an 'our' stance in recognizing and dealing with broader issues. The third-and fifth-grade teachers took a really big hit when standardized test results came back low. Instead of getting stuck on the current test results, the faculty-all grade levels - began framing the problem and the issues, and they generated solutions they could implement and chart results.

Deci reported that often she felt like offering solutions to seemingly endless discussions; yet she knew if she were to interfere, the teachers would simply wait for solutions-they would not seek and struggle with tough issues in the future. Deci had to learn to listen to her teachers, and she often had to reexamine procedures and sitelevel policies to clear the way for more creative solutions to be put in place. She and Jackson wondered whether, at times, they were perceived as being weak because they had to revisit past decisions to honor what teachers wanted to do now. This was a struggle that, according to Jackson, "was worth the stray perceptions if we are helping teachers take control of their professional lives."

\section{Dialogue}

The opportunities for teachers to talk helped "glue" the learning community together. Initially, the pre- and post-observation classroom conferences were the primary means to foster dialogue. Senge (1990, 10) asserted that the "discipline of team learning starts with 'dialogue' - the capacity of members of a team to suspend as- 
sumptions and enter into genuine thinking together."

As one teacher pointed out, "the discussions spilled over to the lunch periods, in the hallways, and after school." Another teacher explained, "Individual differences have been put on the back burner [and] now we are talking about collective ideas that can benefit more than one person or one grade level."

Discussions began to include the values that the members held for the school and its success. Dialogue provided a way for teachers to learn from one another and from the changing context of the school structure at Plymouth Elementary School. One teacher discovered that many procedures [for accessing technology] had to be updated due to his newly developed skills at infusing technology into his lesson plans. Deci said, "This teacher led the battle for getting more resources in place for our school. He was able to convince the curriculum coordinators that our infrastructure needed to be updated." She concluded, "Teacher expertise had to be acknowledged and utilized. No longer did I or Jackson have all the answers.... Our teachers could, at times, get things done more effectively."

More profoundly, however, teachers were expressing their values about students, one another, and the work that was most important for them to accomplish. One teacher said, "I feel like a professional. I feel like my voice is resonating with others who share the same beliefs about students." A fourth-grade teacher explained:

The values of the school were being seen by the actions of the teachers. We started an after-school peer-tutoring program because we believed that all students should be given the help they need to be successful.

Another teacher commented:
The real value of our work is derived from working with one another toward accomplishing good things for kids. Our grade-level members make it a point to observe each other teaching so that we can learn better' what makes kids tick.' We now have a better appreciation for each other's work.

\section{Reflection}

Dialogue was extended through reflection. Teachers indicated that they were more prone to reflect on their practices and inquire more deeply about the issues of teaching and learning because of the dialogue encouraged through pre- and postobservation conferences, results from action research, and discussions at weekly faculty meetings. Objective data collected by a peer, an administrator, or from action research provided content for reflection. One teacher put it this way, "Tinkering with my thinking has kept me focused on how my practices have evolved and changed this past year."

A group of second-grade teachers began studying the issues of cultural diversity to determine whether or not their instruction supported non-majority students. Part of this study included action research where teachers visited one another's classrooms to observe calling-patterns. At the end of the month, each reported on the calling-patterns results. Data suggested that non-majority and ESL students were called on more frequently to answer "information, correct or incorrect" questions, whereas majority students were called on more often to answer higher-order thinking questions that required more elaboration. A trend also was noted that, in science and math, boys were called on to correct erroneous responses given by female students. By knowing these trends, teachers were able to reflect on their practices and make necessary changes. 


\section{ZEPEDA}

Several teachers indicated that they benefited from reflecting aloud with their peer coaches. Another teacher indicated that she never would have found the time to reflect had it not been for the push from her colleagues. Reflection on practice became part of the school's culture because the principal encouraged it. This influence helped the school reach beyond what was in place at Plymouth Elementary School.

\section{Conclusions}

The conceptual framework that "glued" together the Plymouth Elementary learning community was due, in part, to learning derived by examining practices through supervision. The implementation of peer-mediated supervision and what it entails-inquiry, generative problem solving, dialogue, and reflection-provided the foundation for the work accomplished at Plymouth Elementary School.

Data revealed that the principal's efforts were critical in creating the conditions necessary to build a learning community. Unexpected, gray issues, however, encumbered the move toward a learning community. Past issues had to be acknowledged, and past solutions and decisions revisited. Basic issues, such as establishing trust and rapport with teachers, were the first steps in building a climate conducive to teacher learning. The principal had to recreate positive workplace conditions, which took nearly a full year to achieve. It took another six months for teachers to feel ownership in the process of examining practices that went beyond individual classrooms.

Data also revealed that the principal had to "unlead" (Blase and Blase 1997) as teachers examined which professional practices could encourage the development of a learning community. This finding is consistent with that of Hill, Bullard, Capper, Hawes, and Wilson (1998, 192) who stated, "Leadership needs to be reorganized as a function that is performed by different people at different times, rather than as a role vested in an individual. Leadership rotates among members, depending on who has the appropriate expertise at any one time."

For the principal, any problems created by this shift in role had to be resolved publicly so that she could serve as a model for change and development. The most significant change for the principal was that she had to change her "mental model" of what supervision, staff developprincipal. ment, and evaluation meant for teachers. Similarly, the principal had to recognize that her teachers were, as learners, undergoing growing pains, and that she could not provide the sole instructional leadership needed to change supervision as it had been practiced at Plymouth Elementary School since it opened in 1986. The principal had to learn how to learn so that her teachers could see what learning and grappling with practices was like. As Wick and Leon $(1995,301)$ reported, "Without a leader committed to learning, an organization will never approach its potential for success."

Through collaborative efforts, supervisory practices changed over time. The traditional, administratively driven supervisory model was replaced with collegial and peer-mediated supervision. 
Data also revealed that supervision alone did not help the learning community develop. The principal purposefully had to craft other parallel learning opportunities. Staff development had to be recast in light of what was discovered in classroom observations. Learning opportunities had to reflect the core values the teachers developed-all teachers are learners, and all students are capable of learning. Teachers had to have built-in mechanisms for experimenting with their learning in a fault-free environment. Further, they had to be anointed and empowered to make critical decisions, and provided the immediate resources necessary to implement decisions. Resources went beyond staff development funds and centered on emotional resources, such as encouragement, reassurance, and time to talk with the principal and others.

\section{RefERENCES}

Acheson, K. A., and M. D. Gall. 1997. Techniques in the clinical supervision of teachers: Preservice and in-service applications, 4th ed. New York: Longman.

Blase, J., and J. Blase. 1997. The fire is back! Principals sharing school governance. Thousand Oaks, Calif.: Corwin Press.

Brookfield, S. D. 1986. Understanding and facilitating adult learning: A comprehensive analysis of principles and effective practices. San Francisco, Calif.: Jossey-Bass.

Brookfield, S. D. 1995. Becoming a critically reflective teacher. San Francisco, Calif.: Jossey-Bass.

Crow, G. M., L. J. Matthews, and L. E. McCleary. 1996. Leadership: A relevant and realistic role for principals. Larchmont, N.Y.: Eye on Education.

Glaser, B. 1978. Theoretical sensitivity: Advances in the methodology of grounded theory. Mill Valley, Calif.: Sociology Press.

Glaser, B., and A. L. Strauss. 1967. The discovery of grounded theory: Strategies for qualitative research. Hawthorne, N.Y.: Aldine de Gruyter Publishing.

Glickman, C. D., S. P. Gordon, and J. M. Ross-Gordon. 1998. Supervision of instruction: A developmental approach, 4 th ed. Boston: Allyn and Bacon.

Guba, Y. 1981. Criteria for assessing the trustworthiness of naturalistic inquiry. Educational Communication and Technology Journal 29(2): 75-91.

Hill, R., T. Bullard, P. Capper, K. Hawes, and K. Wilson. 1998. Learning about learning organizations: Case studies of skill formation in five New Zealand organizations. Learning Organization 5(4): 184-92.

Hord, S. M. 1997. Professional learning communities: Communities of continuous inquiry and improvement. Austin, Tex.: Southwest Educational Development Laboratory.

Jones, B. F., G. Valdez, J. Nowakowski, and C. Rasmussen. 1994. Designing learning and technology for educational reform. Oak Brook, Ill.: North Central Regional Educational Laboratory.
The principal had to relinquish topdown control and give the green light to teachers to move forward in their own learning - by creating and crafting new ways to achieve growth and renewal. The principal also had to struggle with paradoxes in leadership-the perception of her distance toward teachers versus the perception that she was using her position as principal to make growth and development synonymous with supervision-while also trying to develop as a learner.

Supervision was retooled to promote teacher growth and development. One of the most critical aspects of discovering how schools become learning communities for adults is understanding the vital role of the principal. This case study is offered as a means to further the research on the principal's role in building and nurturing a learning community.

Kofman, F., and P. Senge. 1993. Communities of commitments: The heart of learning organizations. Organizational Dynamics 22(2): 5-23.

Lambert, L. 2003. Leadership capacity for lasting school improvement. Alexandria, Va: Association for Supervision and Curriculum Development.

Merriam, S. B. 1998. Qualitative research and case study applications in education. San Francisco, Calif.: Jossey-Bass.

Oxley, D. 1997. Theory and practice of school communities. Educational Administration Quarterly 33(5): 624-43.

Senge, P. M. 1990. The fifth discipline: The art and practice of the learning organization. New York: Doubleday Currency.

Sergiovanni, T. J. 1994. Organizations or communities: Changing the metaphor changes the theory. Educational Administration Quarterly 30(2): 214-26.

Speck, M. and D. A. Stollenwerk. 1999. The principalship: Building a community. Upper Saddle River, N.J.: Prentice-Hall.

Sterling, M. 1998. Building a community week by week. Educational Leadership 56(1): 65-68.

Waite, D. 1995. Rethinking instructional supervision: Notes on its language and culture. London: Falmer Press.

Wald, P. J., and M. S. Castleberry, eds. 2000. Educators as learners: Creating a professional learning community in your school. Alexandria, Va.: Association for Supervision and Curriculum Development.

Wick, C. W., and L. S. Leon. 1995. From idea to action: Creating a learning organization. Human Resource Management 34(2): 299-311.

Zepeda, S. J. 2000. Supervisory practices: Building a constructivist learning community for adults. In Paradigm debates in curriculum and supervision: Modern and postmodern perspectives, ed. J. Glanz and L. Behar-Horenstein, 93-107. Westport, Conn.: Bergin \& Garvey. 